\title{
Elimination of Tumor Cells Using Folate Receptor Targeting by Antibody-Conjugated, Gold-Coated Magnetite Nanoparticles in a Murine Breast Cancer Model
}

\author{
Evan S. Krystofiak, Vyara Z. Matson, Douglas A. Steeber, and Julie A. Oliver \\ Department of Biological Sciences, University of Wisconsin-Milwaukee, Milwaukee, WI 53211, USA \\ Correspondence should be addressed to Julie A. Oliver, joliver@uwm.edu
}

Received 26 May 2012; Accepted 16 July 2012

Academic Editor: Do Kim

Copyright (c) 2012 Evan S. Krystofiak et al. This is an open access article distributed under the Creative Commons Attribution License, which permits unrestricted use, distribution, and reproduction in any medium, provided the original work is properly cited.

Background. The chemotherapeutic treatment of cancer suffers from poor specificity for targeting the tumor cells and often results in adverse effects such as systemic toxicity, damage to nontarget tissues, and development of drug-resistant tumors in patients. Increasingly, drug nanocarriers have been explored as a way of lessening or overcoming these problems. In this study, antibodyconjugated Au-coated magnetite nanoparticles, in conjunction with inductive heating produced by exposure to an oscillating magnetic field (OMF), were evaluated for their effects on the viability of tumor cells in a murine model of breast cancer. Treatment effects were evaluated by light microscopy and SEM. Results. 4T1 mammary epithelial carcinoma cells overexpressing the folate receptor were targeted with an anti-folate receptor primary antibody, followed by labeling with secondary antibody-conjugated Aucoated magnetite nanoparticles. In the absence of OMF exposure, nanoparticle labeling had no effect on $4 \mathrm{~T} 1$ cell viability. However, following OMF treatment, many of the labeled 4T1 cells showed extensive membrane damage by SEM analysis, and dramatically reduced viability as assessed using a live/dead staining assay. Conclusions. These results demonstrate that Au-coated magnetite targeted to tumor cells through binding to an overexpressed surface receptor, in the presence of an OMF, can lead to tumor cell death.

\section{Introduction}

Gold nanoparticles have been used extensively for a wide range of research and medical applications. The utility of these nanoparticles is due in part to the ease with which highly uniform colloidal gold nanoparticles of a specific size can be produced and the wide variety of functionalized nanoparticles that have been described. The majority of proteins that are noncovalently adsorbed onto the surface of colloidal gold nanoparticles retain function [1]. This quality has made colloidal gold nanoparticles a mainstay of biological labeling for both transmission and scanning electron microscopic analysis. In addition, gold nanoparticles have been used for numerous diagnostic applications [2]. Gold nanoparticles have also been used for hyperthermia treatment of tumors. Specifically, gold nanoparticles and nanorods absorb strongly in the near-infrared wavelengths, and release this energy as heat. This bulk heating of cells and tissues has shown some antitumor efficacy $[3,4]$ and has also been combined with traditional chemotherapy to enhance its effects [5]. However, there are significant drawbacks of current hyperthermia protocols, including limited penetration of the near-infrared light to and through the tumor and heat-induced damage to the surrounding normal tissue. Alternatively, an approach that uses highly localized inductive heating could address the issue of nonspecific tissue damage. This could be accomplished by the active targeting of nanoparticles composed of a magnetic iron oxide, such as magnetite or maghemite, to the cell surface membrane and subsequent exposure to an oscillating magnetic field (OMF). Heating in the region of the membrane-bound nanoparticles would then cause cell damage and, potentially, cell death. Magnetite nanoparticles that are coated with gold would offer advantages of both materials-inductive heating in an 
OMF and relatively easy conjugation with virtually all types of proteins that could be used for specific tumor targeting.

A major hurdle to the use of nanoparticles in vivo is their efficient localization to an appropriate target site, such as a tumor. In some cases, passive targeting of nanoparticles to solid tumors can occur through a mechanism termed the "enhanced permeability and retention" (EPR) effect [6]. The EPR effect allows the accumulation of nanoparticles in the tumor due to the increased permeability of the newly formed blood vessels feeding the tumor and a relative lack of lymphatic vessels draining it. However, passive targeting of tumors is far from precise or reliable, and thus intense research effort has focused on developing active targeting mechanisms. Many active targeting strategies have been employed to direct the localization of nanoparticles, including targeting cell-surface markers or receptors on the tumor cells, or targeting the blood vessels supplying the tumor. True tumor-specific markers are rare, and therefore most active targeting strategies take advantage of cell surface molecules that are relatively overexpressed on tumor cells as compared to normal cells. One of the molecules most widely used for active targeting is the folate receptor (FR) [7]. The essential vitamin folate is taken up by a number of folate binding proteins, among which the reduced folate carrier is the most ubiquitously expressed in normal tissues and responsible for the majority of physiologic folate uptake [8]. By contrast, the high-affinity FR has a more restricted expression pattern in normal tissues but is often highly expressed in tumor tissues including breast, ovarian, cervical, brain, nasopharyngeal, colon, renal, and lung $[7,9]$. This increased expression of FR likely supports the increased need for folate by the rapidly dividing tumor cells. Indeed, studies have reported a positive correlation between increased FR expression levels and a poor prognosis for cancer patients $[10,11]$. The FR is not accessible to the blood stream in normal tissues due to its localization to the apical surface of polarized epithelium [12]. However, transformed cells loose their polarization, thus making FR available to agents introduced via the blood stream. Together with its high-level expression in many tumors, this makes the FR a highly attractive molecule for directed tumor targeting. Therefore, many groups, including ours, have used folic acid to functionalize a variety of vesicles and nanoparticles to selectively target tumor cells.

In this study, direct targeting of FR expressed on murine 4T1 tumor cells was performed using antibody-conjugated, Au-coated magnetite nanoparticles. The murine 4T1 mammary epithelial carcinoma is a widely used model of human breast cancer [13]. The 4T1 tumor shares many features of human stage IV breast cancer including metastatic behavior in mice, with spontaneous metastasis to lymph nodes, lung, liver, bone, and brain while the primary tumor is still growing [14-17]. Importantly, 4T1 cells overexpress FR, and we have successfully used folic acid-functionalized vesicles and nanoparticles to target and deliver chemotherapeutic drugs to these cells [18-22]. In addition to using ligands for targeting of FR, antibodies directed against the receptor can be used effectively for selective targeting $[23,24]$. Through use of antibody-conjugated, Au-coated magnetite nanoparticles, efficient and rapid killing of the targeted tumor cells was accomplished by exposure of the labeled cells to an OMF. Significant cell membrane damage assessed by low-voltage, high-resolution scanning electron microscopy (SEM) was correlated with dramatically reduced cell viability. These results demonstrate the potential use of targeted magnetic nanoparticles to selectively kill tumor cells.

\section{Materials and Methods}

2.1. Cell Culture. The murine 4T1 breast tumor cell line, which was originally isolated from a spontaneous breast tumor in BALB/c mice [13], was obtained from ATCC (Manassas, VA, USA) and maintained in RPMI 1640 medium, supplemented with 10\% FBS (Atlanta Biologicals, Lawrenceville, GA, USA), $2 \mathrm{mM}$ L-glutamine, 100 units $/ \mathrm{mL}$ penicillin, $100 \mu \mathrm{g} / \mathrm{mL}$ streptomycin, and $55 \mu \mathrm{M} 2$-mercaptoethanol (all from Life Technologies, Grand Island, NY, USA). The cells were subcultured at $70 \%$ confluency.

\subsection{FR Expression}

2.2.1. Flow Cytometry. 4T1 cells were cultured and lifted using Cellstripper (Mediatech, Manassas, VA, USA) prior to antibody labeling. Cells $\left(0.5 \times 10^{6}\right)$ were labeled with polyclonal rabbit anti-mouse/rat/human FR IgG (FL-257, Santa Cruz Biotechnology, Santa Cruz, CA, USA) diluted to $10 \mu \mathrm{g} / \mathrm{mL}$ in culture medium for 30 minutes on ice. The cells were washed with $2 \%$ normal horse serum in PBS (PBS/NHS) and labeled with polyclonal DyLight 649conjugated goat anti-rabbit $\operatorname{IgG~} \mathrm{F}\left(\mathrm{ab}^{\prime}\right)_{2}$ fragment (Jackson ImmunoResearch Laboratories, West Grove, PA, USA) secondary antibody diluted to $7.5 \mu \mathrm{g} / \mathrm{mL}$ in PBS/NHS for 30 minutes on ice. Control cells were incubated in the secondary antibody alone. Following labeling, the cells were washed as above, fixed in $1.5 \%$ formaldehyde in PBS, and analyzed using a FACSCalibur flow cytometer (BD Biosciences, San Jose, CA, USA). Ten thousand cells/sample were analyzed with fluorescence intensity displayed on a 4-decade log scale.

2.2.2. Fluorescence Microscopy. $4 \mathrm{~T} 1$ cells $\left(0.15 \times 10^{6}\right)$ were cultured on $10 \mathrm{~mm}$ round no. 1.5 glass coverslips (Ted Pella, Redding, CA, USA) for 18 hours. Coverslips were labeled as above except that incubations were performed at $37^{\circ} \mathrm{C}$. Following labeling, cells were fixed in $1.5 \%$ formaldehyde in PBS, mounted on glass slides in ProLong Gold (Life Technologies), and analyzed on a Nikon Eclipse TE2000$\mathrm{U}$ inverted epifluorescence microscope. Digital monochromatic images were acquired at a constant exposure setting through a Nikon Plan Apo 60x oil immersion objective using a CoolSNAP ES CCD camera (Photometrics, Tucson, AZ, USA) and MetaVue software (Universal Imaging Corporation, Downingtown, PA, USA).

\subsection{Au and Au-Coated Magnetite Nanoparticles}

2.3.1. Synthesis. All reagents were of ACS grade or higher. Colloidal gold nanoparticles with an average diameter of 
approximately $18 \mathrm{~nm}(18 \mathrm{~nm} \mathrm{Au})$ were prepared as previously described [25]. Magnetite nanoparticles were prepared by an aqueous coprecipitation method [26] using a solution containing $0.64 \mathrm{M}$ anhydrous $\mathrm{FeCl}_{3}$ and $0.32 \mathrm{M}$ anhydrous $\mathrm{FeCl}_{2}$ (both salts from Sigma-Aldrich, St. Louis, MO, USA) in $0.4 \mathrm{M} \mathrm{HCl}$ under argon. Five $\mathrm{mL}$ was added to $50 \mathrm{~mL}$ of $1.5 \mathrm{M} \mathrm{NaOH}$, and the resultant magnetite was allowed to settle. Nanoparticles were washed by centrifugation at $3,000 \mathrm{~g}$ three times in degassed water and once in $0.1 \mathrm{M}$ tetramethylammonium hydroxide (Alfa Aesar, Ward Hill, MA, USA). Nanoparticles remaining in suspension following a final $6000 \mathrm{~g}$ centrifugation were aged at least three days in $0.1 \mathrm{M}$ tetramethylammonium hydroxide before coating with gold. Gold growth on the magnetite was initiated by adding $120 \mu \mathrm{L}$ of a $4 \% \mathrm{HAuCl}_{4} \cdot 3 \mathrm{H}_{2} \mathrm{O}$ (Sigma-Aldrich) solution to $100 \mathrm{~mL}$ nanoparticles diluted $1: 100$ in $0.00275 \%$ hydrazine hydrate (Sigma-Aldrich) with stirring, similar to the procedure described in [27]. The resultant Au-coated magnetite nanoparticles were of a diameter similar to that of the Au nanoparticles, with batch averages ranging from 16 to $22 \mathrm{~nm}$.

\subsubsection{Conjugation of Secondary Antibody to Nanoparticles.} Antibody conjugation to nanoparticles was as previously described [28]. Briefly, conjugation of goat anti-rabbit IgG $\mathrm{F}\left(\mathrm{ab}^{\prime}\right)_{2}$ fragments (Jackson ImmunoResearch) to $18 \mathrm{~nm} \mathrm{Au}$ nanoparticles was performed at $\mathrm{pH} 9.5$ and $10 \mu \mathrm{g} / \mathrm{mL}$ final protein concentration. Goat anti-rabbit IgG $(\mathrm{H}+\mathrm{L}$, Southern Biotech, Birmingham, AL, USA) was conjugated to both $\mathrm{Au}$ and $\mathrm{Au}$-coated magnetite nanoparticles at $\mathrm{pH} 7.0$ and $20 \mu \mathrm{g} / \mathrm{mL}$ final protein concentration. All nanoparticle conjugates were stabilized by addition of $0.004 \%$ final concentration polyethylene glycol (average MW 20,000, SigmaAldrich). After conjugation, free protein was removed by centrifugation at $16,000 \mathrm{~g}$ for 5 minutes to pellet the nanoparticles. The nanoparticles were resuspended in HBSS supplemented with $2 \mathrm{mM} \mathrm{Ca}^{2+}$ to an approximate concentration of $2.5 \times 10^{12}$ particles $/ \mathrm{mL}$ for $\mathrm{Au}$ and $2.2 \times 10^{12}$ particles $/ \mathrm{mL}$ for Au-coated magnetite. The maximum possible final antibody concentration was $100 \mu \mathrm{g} / \mathrm{mL}$ for the whole molecule and $50 \mu \mathrm{g} / \mathrm{mL}$ for the $\mathrm{F}\left(\mathrm{ab}^{\prime}\right)_{2}$ fragment.

\subsection{Cell Targeting and Killing Assays}

2.4.1. Cell Labeling with Nanoparticles. $4 \mathrm{~T} 1$ cells $(0.15 \times$ $10^{6}$ ) were cultured on $13 \mathrm{~mm}$ round Thermanox coverslips (Nalge Nunc Int., Rochester, NY, USA) for 18 hours prior to labeling. Cells were labeled with polyclonal rabbit anti-FR (FL-257) IgG diluted to $10 \mu \mathrm{g} / \mathrm{mL}$ in culture medium for 30 minutes at $37^{\circ} \mathrm{C}$. Cells were washed three times in PBS/NHS. Secondary label incubation with freshly-prepared $\mathrm{Au}$ or $\mathrm{Au}-$ coated magnetite nanoparticle conjugates was for 12 minutes at $37^{\circ} \mathrm{C}$. After labeling, cells were washed three times in HBSS containing $2 \mathrm{mM} \mathrm{Ca}^{2+}$.

2.4.2. OMF Treatment. Cells exposed to the OMF were placed in a water-cooled device coil designed and built inhouse. The system includes a RF amplifier (T\&C Power
Conversion, Rochester, NY, USA), a hand-turned copper coil, and a series of fixed capacitors in parallel with a variable capacitor. For OMF treatment, samples were exposed to an $8 \mathrm{mT}, 500 \mathrm{kHz}$ field for 12 minutes. The temperature of the coil and cooling water was monitored during this time and never exceeded $30^{\circ} \mathrm{C}$. Control samples that were not exposed to the OMF were incubated at room temperature for the same length of time, well outside the area where the magnetic field could be detected.

2.4.3. SEM Preparation and Imaging. Cells were fixed in $1 \%$ glutaraldehyde, $1 \%$ tannic acid in 0.1 M HEPES, pH 7.3, for 30 minutes. The samples were washed 3 times in $0.1 \mathrm{M}$ HEPES and postfixed in $0.05 \% \mathrm{OsO}_{4}$ in $0.1 \mathrm{M}$ HEPES for 15 minutes. Samples were dehydrated using a graded ethanol series and dried using the critical point drying method. Specimens were made conductive by sputtering $4 \mathrm{~nm}$ Ir onto their surface. Imaging was performed on a Hitachi S-4800 SEM at $1 \mathrm{kV}$ for secondary and $25 \mathrm{kV}$ for backscattered electron signals.

2.4.4. Cell Viability Assay. Cell viability after labeling and/or OMF exposure was assessed following incubation in culture medium containing calcein-AM ( $1 \mu \mathrm{M}$, Life Technologies) and propidium iodide (PI, $1 \mu \mathrm{g} / \mathrm{mL}$, Sigma-Aldrich) for 30 minutes at $37^{\circ} \mathrm{C}$ as previously described [29]. The samples were analyzed by epifluorescence microscopy using a Nikon Plan Apo 20x objective as described above.

\section{Results}

3.1. FR Expression on $4 T 1$ Tumor Cells. To monitor FR expression on 4T1 tumor cells, cells were labeled with antibody against FR and analyzed by fluorescence microscopy and flow cytometry. 4T1 cells demonstrated strong staining for FR that occurred in a distinctive punctate pattern on the cell membrane (Figure 1(a)). All cells in the sample appeared to express FR at a relatively equivalent level of intensity. To quantify the level of FR expression, 4T1 cells were labeled and analyzed by flow cytometry. Results showed that $>95 \%$ of 4T1 cells expressed FR and that expression was uniform in the population (Figure 1(b)). Therefore, 4T1 tumor cells were used for development of FR-targeted therapy using $\mathrm{Au}-$ coated magnetite nanoparticles.

3.2. Nanoparticle Labeling of FR. To determine the efficiency of nanoparticle targeting to $4 \mathrm{~T} 1$ cells via the FR, cells were labeled with FR-specific antibody followed by secondary antibody nanoparticle conjugates and were analyzed by SEM. Both $18 \mathrm{~nm}$ Au conjugates, which are routinely used for biological labeling and can be considered as a standard, and Au-coated magnetite conjugates were used. Figures 2(a)2(c) show labeling with $18 \mathrm{~nm}$ Au conjugates of goat antirabbit $\operatorname{IgG~F}\left(\mathrm{ab}^{\prime}\right)_{2}$ fragments. In agreement with the punctate pattern observed by light microscopy, specific labeling was found to occur in nanoparticle clusters. These are especially apparent in backscattered electron images (Figure 2(c)), in which features composed of higher atomic number elements 

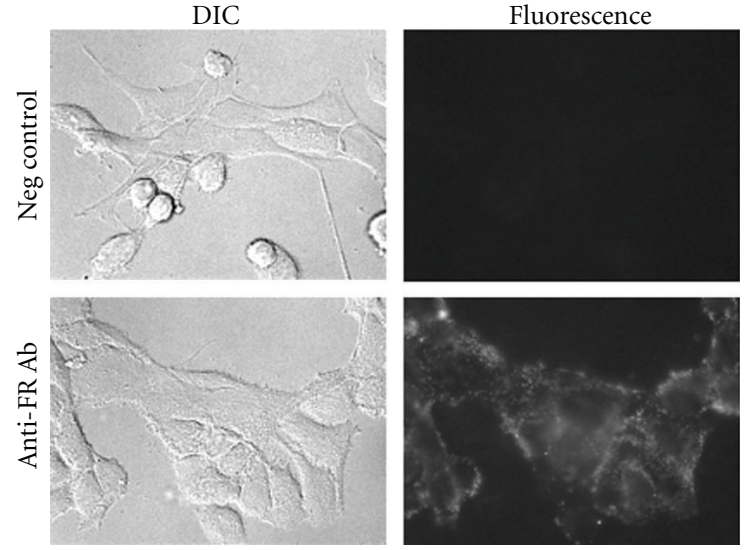

(a)

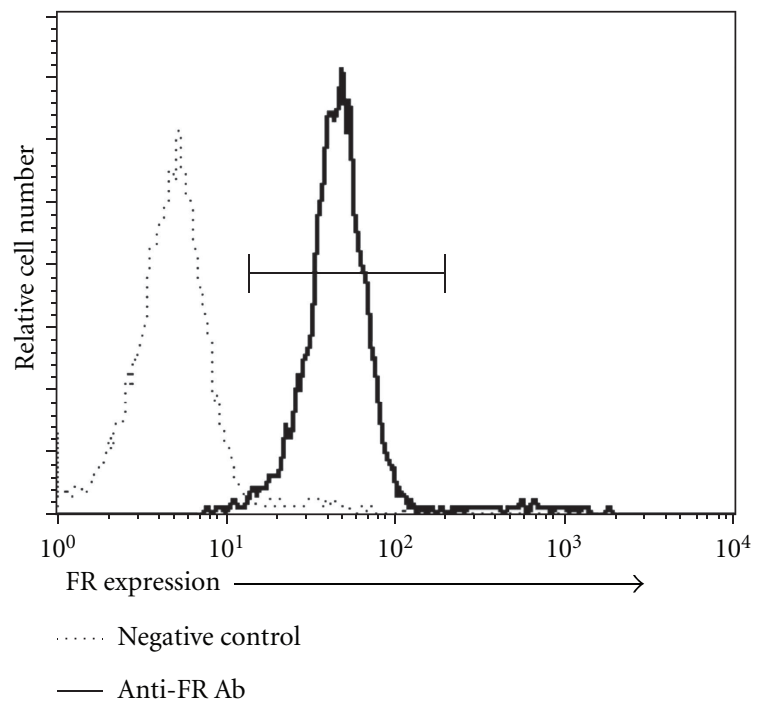

(b)

FIGURE 1: FR expression by 4T1 cells. (a) 4T1 cells were labeled with anti-FR antibody. Left panels show differential interference contrast (DIC) images; right panels show the fluorescence image of the same field. Negative control cells were labeled with the secondary antibody alone. Images were taken at $600 \mathrm{x}$ magnification. (b) Cells were labeled as above and analyzed by flow cytometry. Marker indicates positive staining for FR.

(e.g., Au nanoparticles) appear brighter than their organic surroundings. Nanoparticle clusters were found on both the cell body and on microvilli. Control cells incubated with the $\mathrm{Au}$ conjugates, but without FR-specific antibody, demonstrated minimal nanoparticle binding to their surface (not shown). Nanoparticle clustering was not observed in the control samples. FR labeling detected with Au-coated magnetite conjugates of goat anti-rabbit IgG showed a pattern indistinguishable from that observed with $\mathrm{Au}$ conjugates (Figures 2(d)-2(f)).

3.3. SEM Studies of OMF-Induced Effects. Exposing labeled cells to the OMF produced effects dependent on the type of nanoparticles used. Cell damage was readily observed in samples that were targeted with Au-coated magnetite nanoparticles. Examples of the type of cell damage that resulted from exposing cells labeled with Au-coated magnetite specifically targeted to the FR to the OMF are shown in Figure 3. Cell remnants, or "ghosts," (Figure 3(a)) could be found. The most common type of damage observed was unusually flat cells that appeared to have been emptied of their contents (Figures 3(b) and 3(c)). Nanoparticle clusters were often found very near to or associated with these cells. The amount of membrane-bound cellular debris was higher on the samples labeled with specifically targeted Aucoated magnetite nanoparticles and exposed to the OMF (Figures 3(d) and 3(e)) than that in control samples. Clusters of nanoparticles were frequently found associated with the debris, suggesting that the material originated from the membranes of labeled cells. Control cells labeled with nonmagnetic Au conjugates and exposed to the OMF showed no differences from unlabeled cells with or without OMF treatment, cells labeled with either $\mathrm{Au}$ or Au-coated magnetite conjugates but not exposed to the OMF, or cells labeled with Au-coated magnetite conjugates but lacking primary antibody specific for the FR (not shown). Thus, both magnetite and specific targeting antibody were required to produce visible results in our system.

A potential means by which the cell damage occurs can be seen in Figure 4, which shows a highly damaged cell surrounded by significant debris. Closer inspection demonstrates that the membrane is absent in multiple areas, revealing what appears to be the underlying cytoskeleton. Nanoparticle clusters are closely associated with the regions in which cytoskeleton has been exposed. The loss of membrane that has been damaged in areas near the Au-coated magnetite labels is likely to be a result of localized inductive heating during exposure to the OMF.

3.4. Viability Assay. To determine the extent to which Aucoated magnetite nanoparticle-mediated membrane damage to the 4T1 cells following exposure to OMF produced cytotoxicity, cells were labeled, exposed to the OMF, and incubated with calcein-AM and PI. Calcein-AM is membrane permeable and nonfluorescent but is rapidly hydrolyzed by intracellular esterases and converted to the highly fluorescent molecule calcein. Calcein is membrane impermeable and is thus concentrated in the cytoplasm, thereby staining live cells green. PI is an intercalating dye that has intense red fluorescence when bound to double-stranded DNA or RNA. Since PI is membrane impermeable, it only stains cells that are dead or have membrane damage that allows its access to the cell interior. 4T1 cells labeled using $18 \mathrm{~nm} \mathrm{Au}$ nanoparticles, with or without exposure to the OMF, showed no change in viability compared to that of unlabeled control cells (not shown). Similarly, 4T1 cells labeled with Au-coated magnetite nanoparticles and not exposed to the OMF showed high viability with only the occasional dead cell (Figure 5). By contrast, 4T1 cells labeled with $\mathrm{Au}$-coated magnetite nanoparticles and exposed to the OMF had dramatically reduced viability, with the majority 


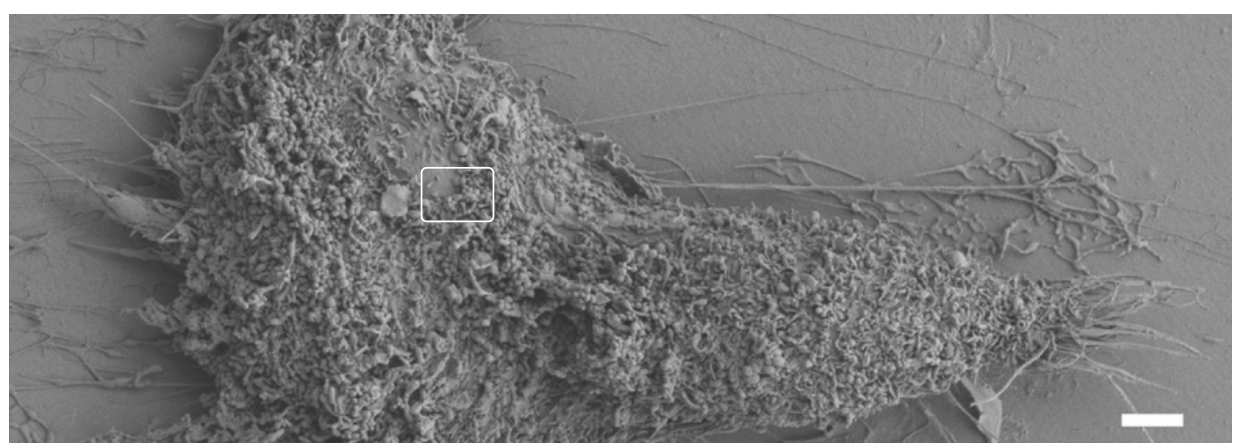

(a)

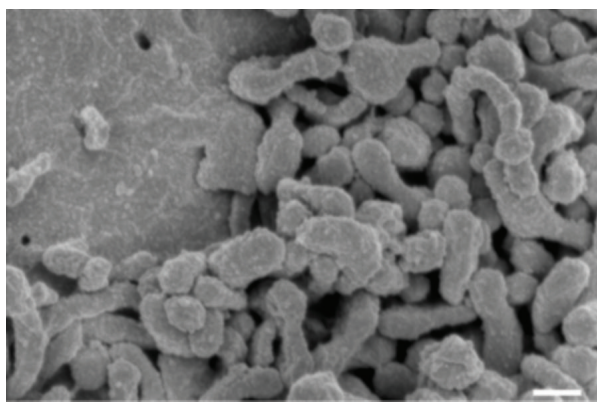

(b)

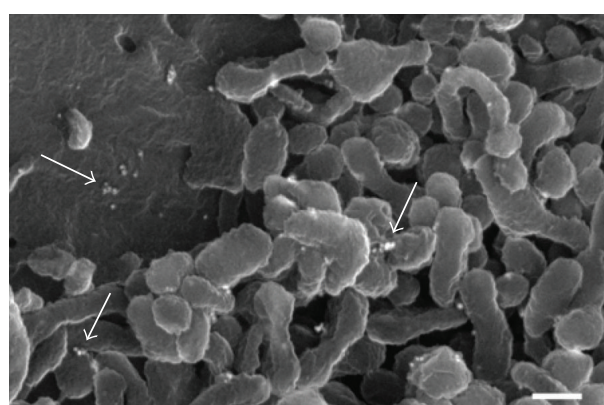

(c)

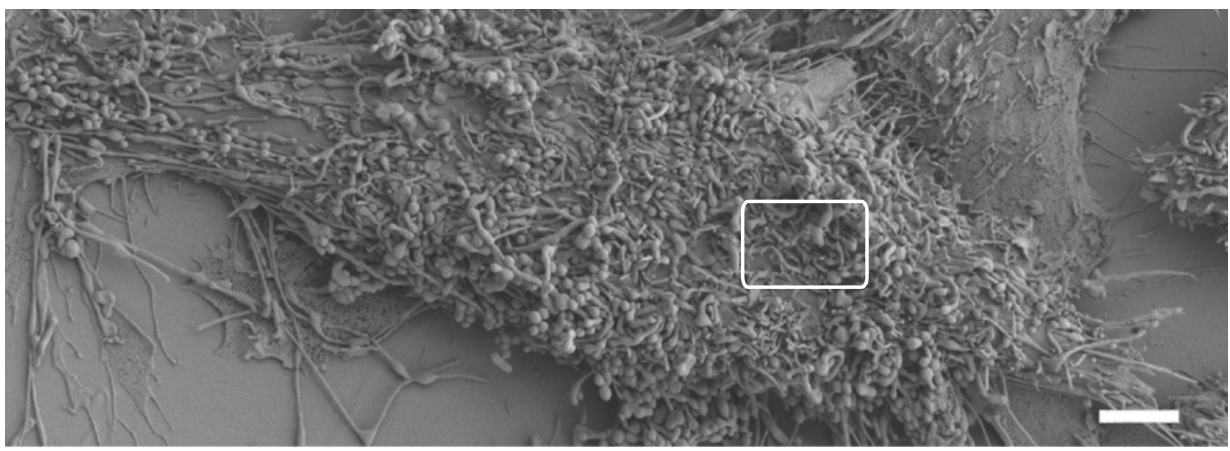

(d)

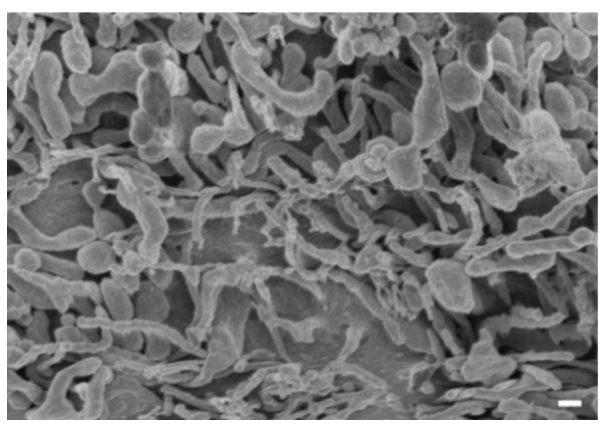

(e)

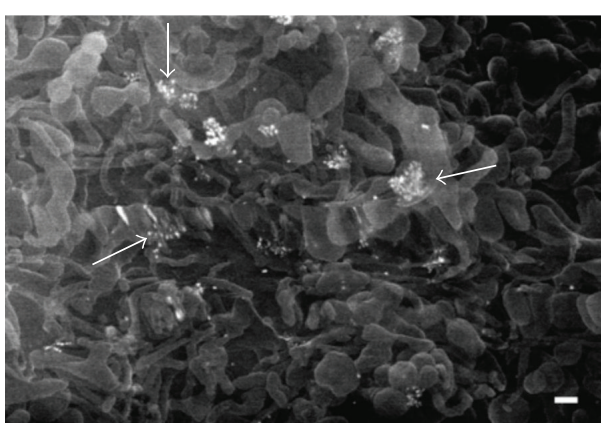

(f)

FIGURE 2: Detection of FR using secondary antibody conjugated to Au-coated magnetite is indistinguishable from that done using $18 \mathrm{~nm}$ Au conjugates. (a)-(c) labeling with Au conjugate; (d)-(f) labeling with Au-coated magnetite conjugate. (a) and (d) Representative 4T1 cell morphology; size bars $=2 \mu \mathrm{m}$. The areas indicated by the white boxes are shown in higher magnification in (b) and (e) as secondary electron images, and in (c) and (f) as backscattered electron images. Arrows in the backscattered images indicate clusters of nanoparticles. Size bars in (b)-(c) and (e)-(f) $=0.2 \mu \mathrm{m}$. 


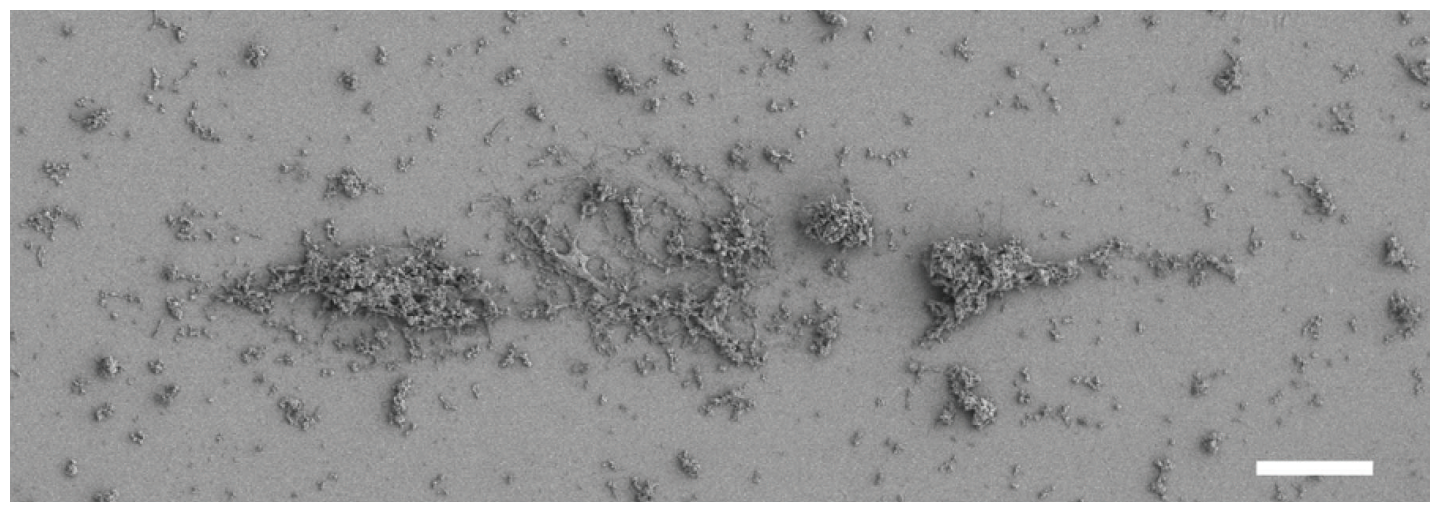

(a)

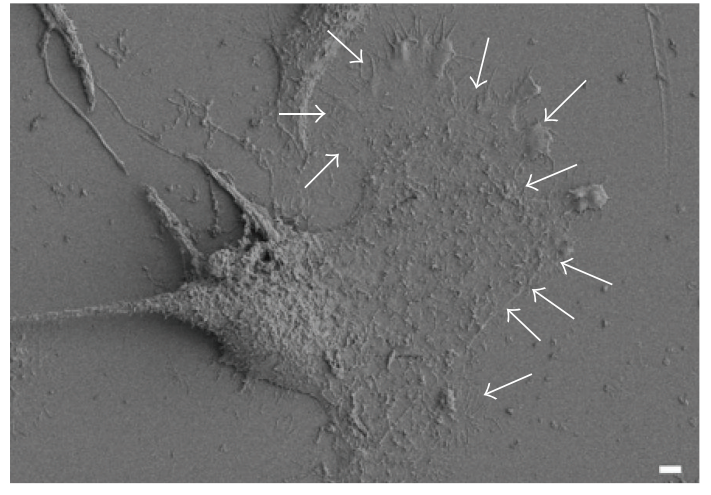

(b)

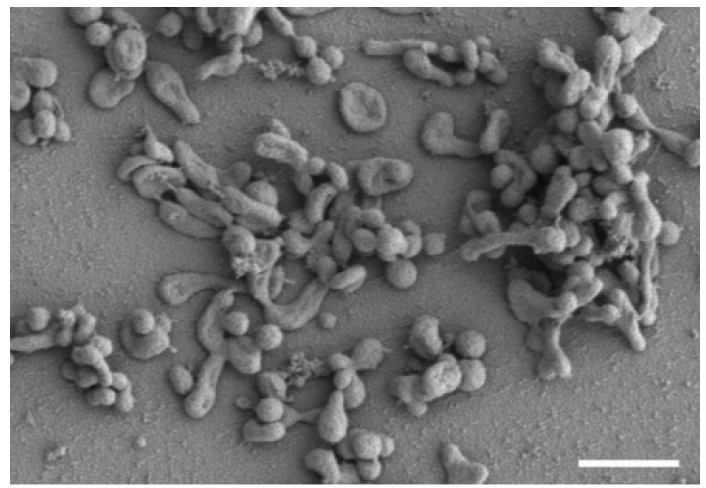

(d)

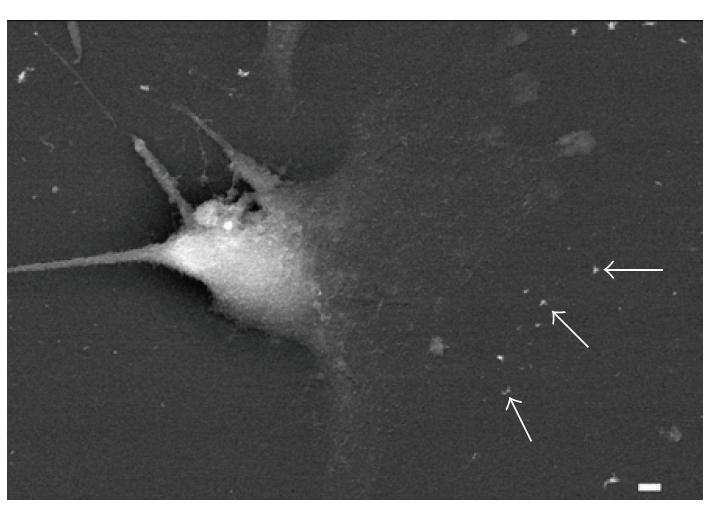

(c)

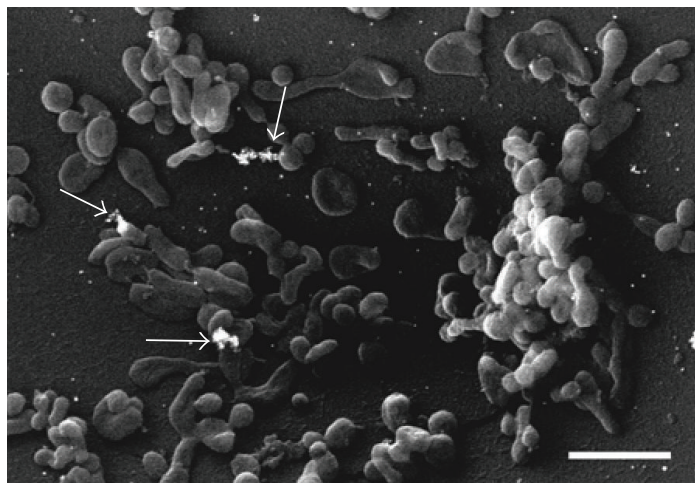

(e)

Figure 3: Labeling with targeted Au-coated magnetite, followed by exposure to the OMF, produces damage to cells. (a) Cell remnant or "ghost." (b)-(c) Secondary and backscattered images, respectively, of a cell with an unusually flat appearance. Arrows in (b) delineate the perimeter of the damaged portion of the cell. Arrows in (c) indicate nanoparticle clusters either associated with the edge of the cell membrane, or possibly left behind as the damaged membrane retracted. (d)-(e) Membranous debris commonly found on specifically labeled samples following exposure to the OMF. (d) Secondary image, (e) backscattered image. Arrows in (e) indicate nanoparticle clusters. Size bars: (a) = $10 \mu \mathrm{m}$; (b)-(c) $=2 \mu \mathrm{m}$; (d)-(e) $=1 \mu \mathrm{m}$.

of the cells staining with PI. Increased presence of what appeared to be cellular debris was observed on these samples, in agreement with results from SEM analysis. These results clearly demonstrate that FR-targeting of magnetic nanoparticles and application of an OMF can effectively kill tumor cells in vitro.

\section{Discussion}

The results presented in this study demonstrate that FR expressed on tumor cells can be effectively labeled by Aucoated magnetite nanoparticles in a manner indistinguishable from that seen with $18 \mathrm{~nm}$ Au. Labeled cells exposed to 


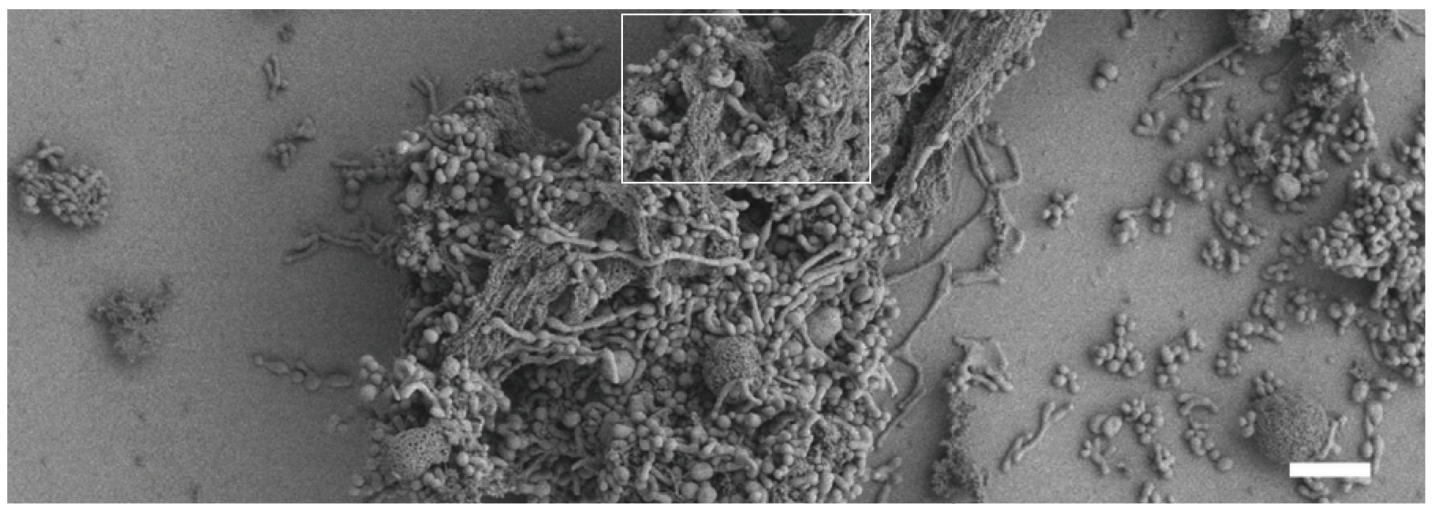

(a)

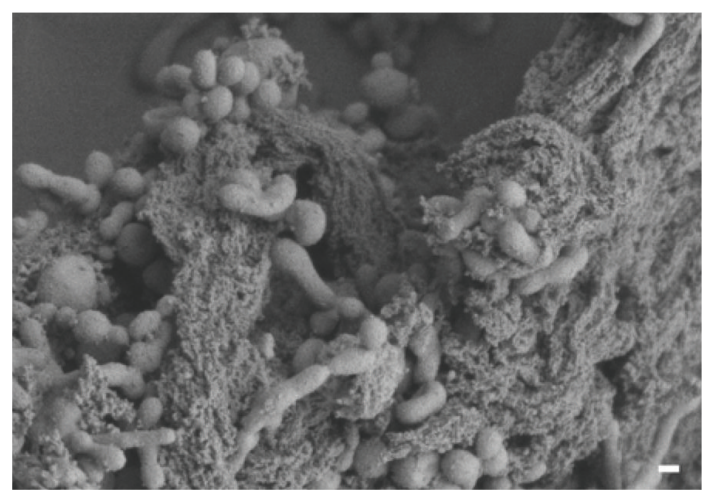

(b)

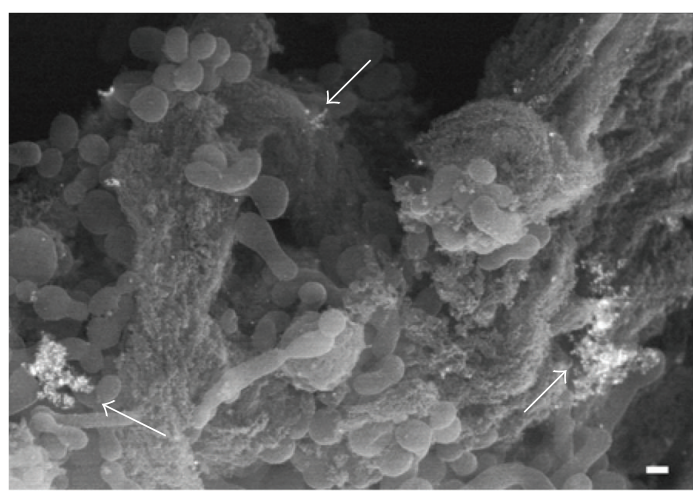

(c)

FIGURE 4: Nanoparticle clusters are found closely associated with areas of membrane damage that reveal the underlying cytoskeleton. (a) Morphology of the damaged cell. The area in the box is seen in higher magnification in (b) as a secondary image and (c) as a backscattered image. Arrows indicate nanoparticle clusters. Size bars: (a) $=2 \mu \mathrm{m}$; (b)-(c) $=0.2 \mu \mathrm{m}$.
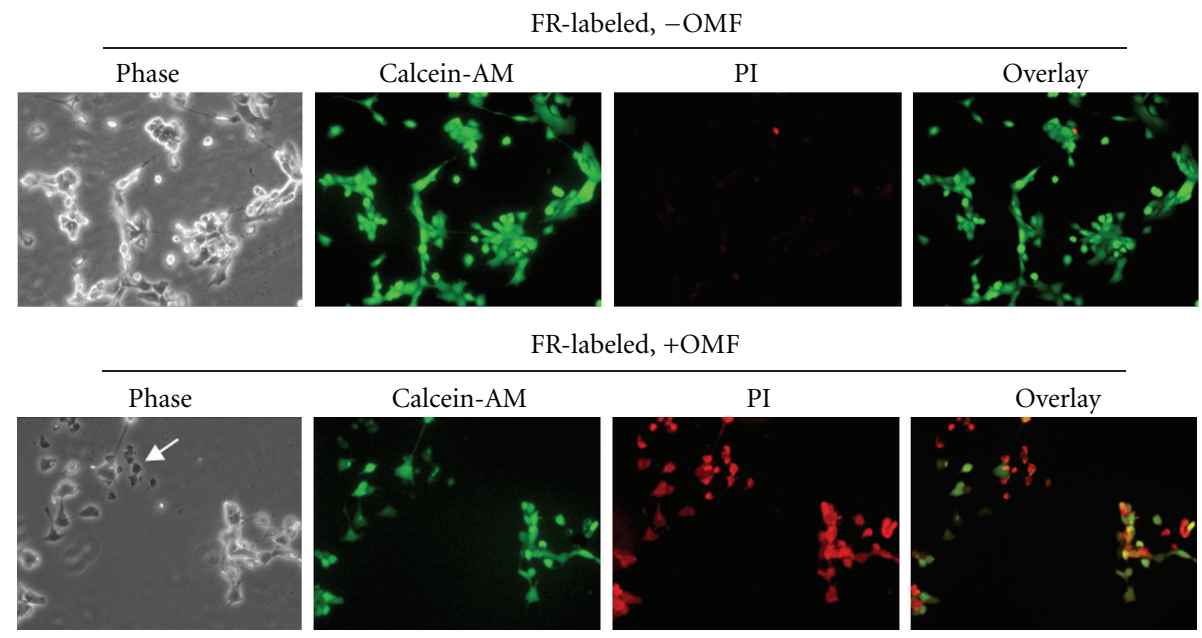

FIGURE 5: $4 \mathrm{~T} 1$ cells were labeled for FR using Au-coated magnetite nanoparticles without (-OMF, upper panels) or with (+OMF, lower panels) exposure to the OMF prior to staining with calcein-AM and PI. In the overlay, yellow indicates colocalization of green and red fluorescence. Apparent cell debris or cell remnants are indicated by the arrow in the lower phase image. Images taken at 200x magnification. 
an OMF experienced damage that was dependent upon the presence of both the magnetic iron oxide and the magnetic field. The damage observed by SEM analysis was accompanied by a dramatic reduction in cell viability. Thus, specific killing of the carcinoma cells was accomplished.

The potential treatment described here has numerous advantages over other approaches. Highly localized inductive heating in the area immediately surrounding the labels on the targeted tumor cell surface largely avoids bulk heating effects that would damage surrounding normal tissue. To exert killing, passively targeted nanoparticles depend on nonspecific concentration within the tumor. Whether utilizing a hyperthermia or drug delivery approach, normal cells in the vicinity of the nanoparticles would be susceptible to damage or killing. The present method relies on damage to the labeled cell membrane, previously described as "membrane melting" [30], which then results in a loss of cell viability. Theoretically, an unlabeled normal cell next to the tumor cell would not show effects. Studies investigating this are currently underway. In addition, direct conjugation of the FR-specific antibody to the Au-coated magnetite nanoparticles is likely to be desirable both for localizing nanoparticles more closely to the tumor cell surface and for ease of administration in potential in vivo applications. These experiments will be conducted based on the proof of principle demonstrated here.

While folic acid is more commonly used to target FR on tumor cells, the use of antibody directed against FR may have advantages for the current application. It is generally accepted that FR is diffusely distributed across the cell membrane and upon binding of soluble ligand becomes internalized via the GPI-anchored protein-enriched endocytic compartment (GEEC) pathway [31]. By contrast, antibody cross-linking of FR results in its clustering within caveolae before internalization [32]. This clustering of FR was readily apparent in the present study using both fluorescence- and nanoparticle-mediated detection. Clustered nanoparticles may be more effective in generating localized membrane damage than would occur with diffuse receptor labeling. Further studies are necessary to address this question.

The use of targeted magnetic nanoparticles and inductive heating has the potential to be used alone or in combination with other standard anticancer therapies. For example, one of the major shortcomings of chemotherapy is the development of multidrug resistance (MDR) in tumor cells [33]. Development of MDR is associated with overexpression of a number of transporter proteins that actively efflux a wide array of chemotherapeutic drugs out of the tumor cells, rendering them insensitive to further drug treatment. The use of antibody-targeted therapy (immunotherapy) to overcome MDR in tumor cells is an active area of investigation [34]. The antibody-targeted magnetic nanoparticles described here could be an additional strategy for treating tumor cells that have developed MDR.

\section{Authors' Contribution}

E. S. Krystofiak and V. Z. Matson contributed equally and thus share first authorship.

\section{Acknowledgments}

This work was supported by the American Heart Association Scientist Development Grant 0930253N; the University of Wisconsin-Milwaukee Research Growth Initiative 101X106, the UW-Madison/UW-Milwaukee Intercampus Award PRJ37PH and PRJ37JV (JAO); and National Science Foundation MRI CHE-0723002. The authors wish to thank Dr. Ralph M. Albrecht for helpful discussions.

\section{References}

[1] S. L. Goodman, G. M. Hodges, and D. C. Livingston, "A review of the colloidal gold marker system," Scanning Electron Microscopy, part 2, pp. 133-146, 1980.

[2] A. Kumar, B. M. Boruah, and X. J. Liang, "Gold nanoparticles: promising nanomaterials for the diagnosis of cancer and HIV/ AIDS," Journal of Nanomaterials, vol. 2011, Article ID 202187, 17 pages, 2011.

[3] S. Jain, D. G. Hirst, and J. M. O'Sullivan, "Gold nanoparticles as novel agents for cancer therapy," British Journal of Radiology, vol. 85, no. 1010, pp. 101-113, 2012.

[4] D. K. Chatterjee, P. Diagaradjane, and S. Krishnan, "Nanoparticle-mediated hyperthermia in cancer therapy," Therapeutic Delivery, vol. 2, no. 8, pp. 1001-1014, 2011.

[5] T. S. Hauck, T. L. Jennings, T. Yatsenko, J. C. Kumaradas, and W. C. W. Chan, "Enhancing the toxicity of cancer chemotherapeutics with gold nanorod hyperthermia," Advanced Materials, vol. 20, no. 20, pp. 3832-3838, 2008.

[6] Y. Matsumura and H. Maeda, "A new concept for macromolecular therapeutics in cancer chemotherapy: mechanism of tumoritropic accumulation of proteins and the antitumor agent smancs," Cancer Research, vol. 46, no. 12, part 1, pp. 6387-6392, 1986.

[7] C. P. Leamon and A. L. Jackman, "Chapter 7, Exploitation of the folate receptor in the management of cancer," Vitamins and Hormones, vol. 79, pp. 203-233, 2008.

[8] L. H. Matherly and I. D. Goldman, "Membrane transport of folates," Vitamins and Hormones, vol. 66, pp. 403-456, 2003.

[9] N. Parker, M. J. Turk, E. Westrick, J. D. Lewis, P. S. Low, and C. P. Leamon, "Folate receptor expression in carcinomas and normal tissues determined by a quantitative radioligand binding assay," Analytical Biochemistry, vol. 338, no. 2, pp. 284-293, 2005.

[10] L. E. Kelemen, "The role of folate receptor $\alpha$ in cancer development, progression and treatment: cause, consequence or innocent bystander?" International Journal of Cancer, vol. 119, no. 2, pp. 243-250, 2006.

[11] L. C. Hartmann, G. L. Keeney, W. L. Lingle et al., "Folate receptor overexpression is associated with poor outcome in breast cancer," International Journal of Cancer, vol. 121, no. 5, pp. 938-942, 2007.

[12] Y. Lu and P. S. Low, "Folate-mediated delivery of macromolecular anticancer therapeutic agents," Advanced Drug Delivery Reviews, vol. 54, no. 5, pp. 675-693, 2002.

[13] D. L. Dexter, H. M. Kowalski, B. A. Blazar, Z. Fligiel, R. Vogel, and G.H. Heppner, "Heterogeneity of tumor cells from a single mouse mammary tumor," Cancer Research, vol. 38, no. 10, pp. 3174-3181, 1978.

[14] C. J. Aslakson and F. R. Miller, "Selective events in the metastatic process defined by analysis of the sequential dissemination of subpopulations of a mouse mammary tumor," Cancer Research, vol. 52, no. 6, pp. 1399-1405, 1992. 
[15] B. A. Pulaski, D. S. Terman, S. Khan, E. Muller, and S. OstrandRosenberg, "Cooperativity of Staphylococcal aureus enterotoxin B superantigen, major histocompatibility complex class II, and CD80 for immunotherapy of advanced spontaneous metastases in a clinically relevant postoperative mouse breast cancer model," Cancer Research, vol. 60, no. 10, pp. 2710-2715, 2000.

[16] B. A. Pulaski and S. Ostrand-Rosenberg, "Reduction of established spontaneous mammary carcinoma metastases following immunotherapy with major histocompatibility complex class II and B7.1 cell-based tumor vaccines," Cancer Research, vol. 58, no. 7, pp. 1486-1493, 1998.

[17] M. Lelekakis, J. M. Moseley, T. J. Martin et al., "A novel orthotopic model of breast cancer metastasis to bone," Clinical and Experimental Metastasis, vol. 17, no. 2, pp. 163-170, 1999.

[18] M. Prabaharan, J. J. Grailer, S. Pilla, D. A. Steeber, and S. Gong, "Folate-conjugated amphiphilic hyperbranched block copolymers based on Boltorn $\AA \mathrm{H} 40$, poly(L-lactide) and poly(ethylene glycol) for tumor-targeted drug delivery," Biomaterials, vol. 30, no. 16, pp. 3009-3019, 2009.

[19] M. Prabaharan, J. J. Grailer, D. A. Steeber, and S. Gong, “Thermosensitive micelles based on folate-conjugated poly(N-vinylcaprolactam)-block-poly(ethylene glycol) for tumor-targeted drug delivery," Macromolecular Bioscience, vol. 9, no. 8, pp. 744-753, 2009.

[20] M. Prabaharan, J. J. Grailer, S. Pilla, D. A. Steeber, and S. Gong, "Gold nanoparticles with a monolayer of doxorubicin-conjugated amphiphilic block copolymer for tumor-targeted drug delivery," Biomaterials, vol. 30, no. 30, pp. 6065-6075, 2009.

[21] M. Prabaharan, J. J. Grailer, S. Pilla, D. A. Steeber, and S. Gong, "Amphiphilic multi-arm-block copolymer conjugated with doxorubicin via $\mathrm{pH}$-sensitive hydrazone bond for tumortargeted drug delivery," Biomaterials, vol. 30, no. 29, pp. $5757-$ 5766, 2009.

[22] X. Yang, J. J. Grailer, S. Pilla, D. A. Steeber, and S. Gong, "Tumor-targeting, pH-responsive, and stable unimolecular micelles as drug nanocarriers for targeted cancer therapy," Bioconjugate Chemistry, vol. 21, no. 3, pp. 496-504, 2010.

[23] J. Sudimack and R. J. Lee, "Targeted drug delivery via the folate receptor," Advanced Drug Delivery Reviews, vol. 41, no. 2, pp. 147-162, 2000.

[24] A. Zacchetti, F. Martin, E. Luison et al., "Antitumor effects of a human dimeric antibody fragment 131I-AFRA-DFM5. 3 in a mouse model for ovarian cancer," Journal of Nuclear Medicine, vol. 52, no. 12, pp. 1938-1946, 2011.

[25] J. A. Oliver and R. M. Albrecht, "Colloidal gold labelling of fibrinogen receptors in epinephrine- and ADP-activated platelet suspensions," Scanning Microscopy, vol. 1, no. 2, pp. 745-756, 1987.

[26] R. Massart, "Preparation of aqueous magnetic liquids in alkaline and acidic media," IEEE Transactions on Magnetics, vol. 17, no. 2, pp. 1247-1248, 1981.

[27] J. L. Lyon, D. A. Fleming, M. B. Stone, P. Schiffer, and M. E. Williams, "Synthesis of Fe oxide core/Au shell nanoparticles by iterative hydroxylamine seeding," Nano Letters, vol. 4, no. 4, pp. 719-723, 2004.

[28] R. M. Albrecht, J. A. Oliver, and J. C. Loftus, "Observation of colloidal gold labelled platelet surface receptors and the underlying cytoskeleton using high voltage electron microscopy and scanning electron microscopy," in The Science of Biological Specimen Preparation, M. Mueller, R. P. Becker, A. Boyde, and J. J. Wolosewick, Eds., pp. 185-193, SEM, 1985.
[29] A. Tiwari, J. J. Grailer, S. Pilla, D. A. Steeber, and S. Gong, "Biodegradable hydrogels based on novel photopolymerizable guar gum-methacrylate macromonomers for in situ fabrication of tissue engineering scaffolds," Acta Biomaterialia, vol. 5, no. 9, pp. 3441-3452, 2009.

[30] M. Kaiser, J. Heintz, I. Kandela, and R. Albrecht, “Tumor cell death induced by membrane melting via immunotargeted, inductively heated core/shell nanoparticles," Microscopy and Microanalysis, vol. 13, no. S2, pp. 18-19, 2007.

[31] S. Sabharanjak and S. Mayor, "Folate receptor endocytosis and trafficking," Advanced Drug Delivery Reviews, vol. 56, no. 8, pp. 1099-1109, 2004.

[32] S. Mayor, K. G. Rothberg, and F. R. Maxfield, "Sequestration of GPI-anchored proteins in caveolae triggered by cross-linking," Science, vol. 264, no. 5167, pp. 1948-1951, 1994.

[33] A. K. Tiwari, K. Sodani, C. L. Dai, C. R. Ashby, and Z. S. Chen, "Revisiting the ABCs of multidrug resistance in cancer chemotherapy," Current Pharmaceutical Biotechnology, vol. 12, no. 4, pp. 570-594, 2011.

[34] T. J. Curiel, "Immunotherapy: a useful strategy to help combat multidrug resistance," Drug Resistance Updates, vol. 15, no. 12, pp. 106-113, 2012. 

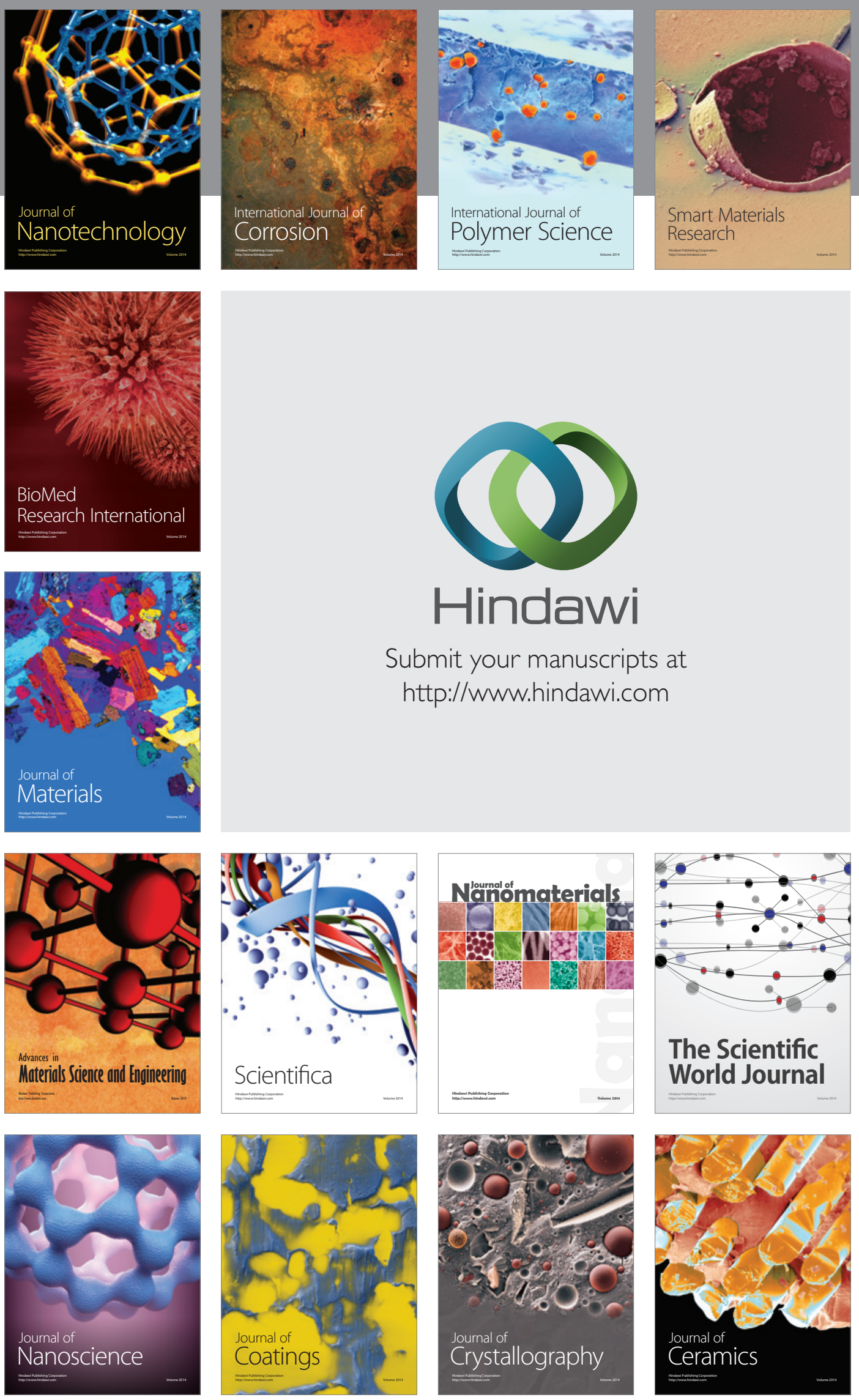

The Scientific World Journal

Submit your manuscripts at

http://www.hindawi.com

\section{World Journal}

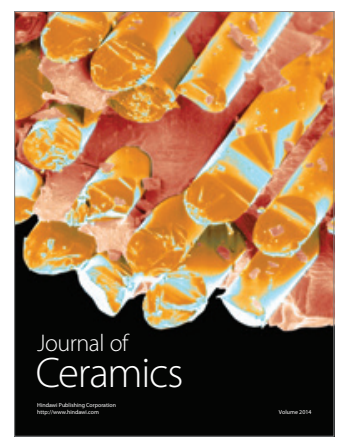

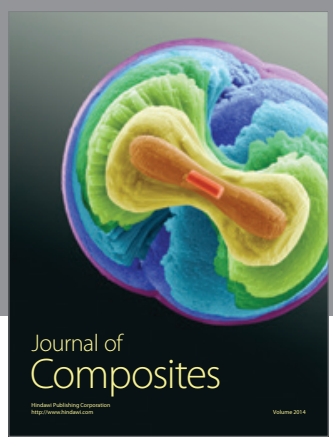
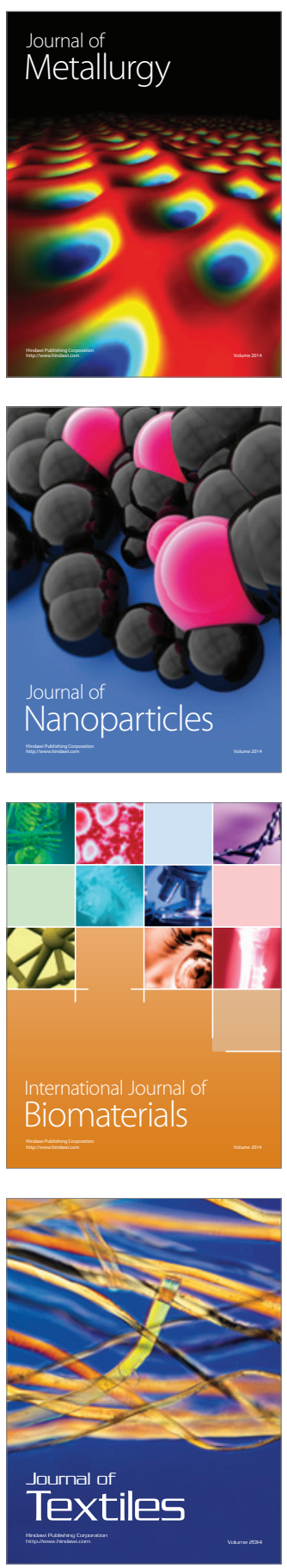